Canadian University Music Review

Canadian University Music Review

Revue de musique des universités canadiennes

\title{
Tonal Organization in Schoenberg's Six Little Piano Pieces, Op.
}

19

\section{Kenneth L. Hicken}

Numéro 1, 1980

URI : https://id.erudit.org/iderudit/1013738ar

DOI : https://doi.org/10.7202/1013738ar

Aller au sommaire du numéro

Éditeur(s)

Canadian University Music Society / Société de musique des universités canadiennes

ISSN

0710-0353 (imprimé)

2291-2436 (numérique)

Découvrir la revue

Citer cet article

Hicken, K. L. (1980). Tonal Organization in Schoenberg's Six Little Piano Pieces, Op. 19. Canadian University Music Review / Revue de musique des universités canadiennes, (1), 130-146. https://doi.org/10.7202/1013738ar

All Rights Reserved (C Canadian University Music Society / Société de musique des universités canadiennes, 1980
Ce document est protégé par la loi sur le droit d'auteur. L'utilisation des services d'Érudit (y compris la reproduction) est assujettie à sa politique d'utilisation que vous pouvez consulter en ligne.

https://apropos.erudit.org/fr/usagers/politique-dutilisation/ 


\title{
TONAL ORGANIZATION IN SCHOENBERG'S SIX LITTLE PIANO PIECES, OP. 19
}

\author{
Kenneth L. Hicken
}

What is the nature of Schoenberg's so-called atonality? Does his atonal organization of pitch truly involve abandonment of tonality and tonal functions, as is widely believed? Or can and should this type of organization be understood as an extension of traditional tonal practice? An appropriate work to examine in consideration of these questions is the Six Little Piano Pieces, Op. 19. In 1911, when they were written, Schoenberg had been composing in his new atonal style for some time, having already completed the monodrama Erwartung (1909), and being just over a year away from the completion of Pierrot Lunaire (1912). Thus, lying as they do between these two atonal milestones, the Op. 19 pieces may be considered a reasonably representative introduction to the composer's atonal language; moreover, their brevity makes them accessible to the analyst.

This study of Op. 19, which has been based on both aural and visual perceptions, finds pitch in this work to be organized much more in terms of extension rather than abandonment of tonality. In the analyses which follow, two basic modes of extension have been observed: (1) "mono-tonal" and (2) "fusedbitonal." The mono-tonal mode, which may be described as "extended tonal chromaticism," predominates: four of the pieces are mono-tonal throughout (Nos. II, III, IV and V) and two are primarily mono-tonal while containing a brief fusedbitonal passage each (Nos. I and VI). Mono-tonal and fusedbitonal modes of organization are described below, then illustrated via harmonic analyses of Pieces II and VI, based upon, as indicated above, both visual and aural considerations. 
As in eighteenth- and nineteenth-century tonal music, pitch is organized with reference to a single tonal center at a time. However, the harmonic "vocabulary" (chords and nonharmonic tones) and "grammar" represent an extension of traditional tonal practice. In a given passage, modulation may or may not occur.

Pitch is organized with reference to two simultaneous tonal centers, some tones being related primarily to one center, some to the other, and generally some to both. The aggregate of tones organized with reference to one center constitutes the "tonal component" of that center, while the aggregate of tones organized with reference to the other center constitutes its tonal component. The two components are often intimately intertwined, part of one component frequently being part of the other as well. The harmonic vocabulary and grammar of each component represent an extension of traditional tonal practice (as in a mono-tonal passage).

A fused-bitonal passage may be regarded as an integration of its tonal components. Accordingly, the harmonic vocabulary and grammar of such a passage may be understood in terms of integration of the harmonic vocabulary and grammar of one component with the harmonic vocabulary and grammar of the other. Chords in a fused-bitonal passage are frequently composites of elements from both components. Infrequently a chord in its entirety belongs equally well to both components.

The following notational practice is used in the harmonic analyses:

1) Tonal centers are indicated by capital letters, any needed accidentals, and colons (e.g., G:, Ab:, etc.).

2) Chords, in most cases, are identified via symbols consisting of Roman numerals and, as needed, Arabic numerals and accidentals, e.g.,

$$
\text { I, IVb3, V } \begin{array}{r}
13 \\
7
\end{array}
$$

Symbols without accidentals, e.g., I, IV ${ }^{9}$, 
designate diatonic chords of the major scale. Roman numerals refer to roots, and Arabic numerals to chord members. Accidentals usually signify chromatic alterations of chord members from their diatonic form. Occasionally accidentals will show that two forms of a chord member occur simultaneously. An Arabic numeral placed directly below a Roman one specifies the chord member occurring in the bass. Chords are often enclosed by curving lines leading from and to the chord symbols themselves.

Examples:

(a) G:I indicates a tonic major triad in G;

(b) G:IVb3 indicates a subdominant triad in $G$ with minor third;

(c) $A b: V \quad 5$ indicates a dominant thirteenth chord in A flat with raised fifth and the seventh of the chord in the bass;

9

(d) $A b::_{b 5} \quad \begin{aligned} & 05 \\ & b 5\end{aligned}$ indicates a supertonic ninth chord in $A$ flat with perfect and flatted fifths and raised third and the flat fifth in the bass.

3) Abbreviations:

anticipation:

an

passing tone:

chromatic passing tone:

neighboring tone:

pt

cpt

incomplete neighboring

tone:

nt

suspension:

int

octave displacement:

Example: pt(8) and sn(8) mean passing tone and suspension, respectively, each with octave displacement in the movement to or from them.

suggested:

sug

Example: Sug I means suggested I.

4) Voice leading is indicated by broken lines terminating in arrow heads. 
5) Measure numbers: In the text, both complete and incomplete measures are listed in which a musical item or passage under discussion occurs.

Piece II illustrates mono-tonal organization without modulation. It is the only piece of the six in which modulation does not occur. Its tonal center is G.

The analysis is initially presented with reference to segments of the piece (Exx. 1-5), and then with reference to the piece as a whole (Exx. 6-7). Occasionally, in keeping with perceived harmonic context, notes in the analysis are spelled as enharmonic equivalents of the corresponding notes in the score. In Examples 1, 2, 3, 5, and 7, original spellings are also indicated in parentheses.

The piece commences by stating the root and the third, and then the third and fifth of the G major triad (Ex. 1a, mm. 1-2). While the root and third of the tonic triad continue to be reiterated $(\mathrm{mm} .2-3)$, a leading-tone diminished-seventh chord is unfolded, one tone at a time: F sharp A C E flat. The third of this chord (A) is then lowered a semitone (m. 3), changing the chord into a German sixth on the flatted supertonic: F sharp A flat C E flat (Ex. 1b). The root and third of the tonic triad continue in their reiteration, embellished by a brief suggestion of subdominant minor harmony in measure 4 (Ex. 1c).

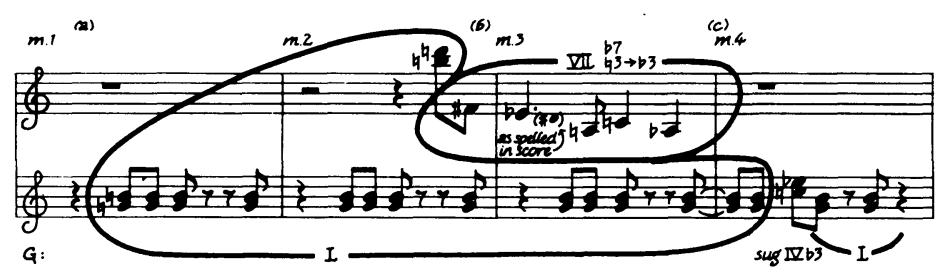

Example 1

As indicated earlier, the harmonic vocabulary in monotonal organization represents an extension of eighteenth- and nineteenth-century practice. One such type of extension is characterized by the occurrence of two different forms of a chord member at once, such as the third, fifth, or seventh, etc. 
An instance of such extension occurs at the beginning of measure 5 in a leading-tone seventh chord which contains two sevenths, one of which is minor, and the other, diminished. The members of this chord are root (F sharp), raised third (A sharp), fifth $(C)$, minor seventh (E), and diminished seventh (E flat). The root and third are repeated later in the measure in a lower register, while elements of tonic harmony continue to be sounded (Ex. 2).

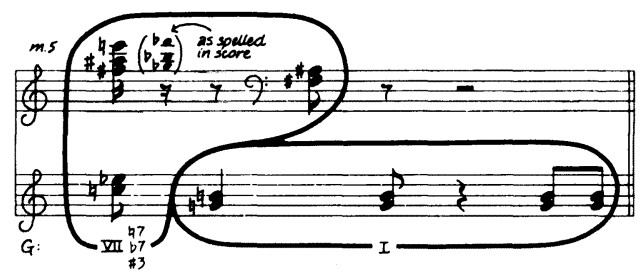

Example 2

A first-inversion dominant-thirteenth chord with minor ninth occurs in measures 6 and 7. Again two forms of a chord member are present simultaneously (Ex. 3), the major and the minor third ( $F$ sharp and $F$ natural, respectively).

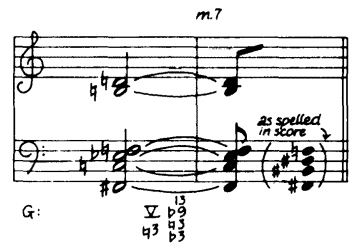

Example 3

Another type of extension of traditional practice is octave displacement in lines which otherwise would move by step or half step. An instance of this occurs in the motion from the root and third of tonic harmony at the end of measure 5 to the root and thirteenth of the dominant thirteenth chord just described. The motion is passing in nature and is embellished with two incomplete neighboring tones. Example 4 illustrates the basic passing motion, then this motion with embellishment, and finally the embellished motion with octave displacement. 


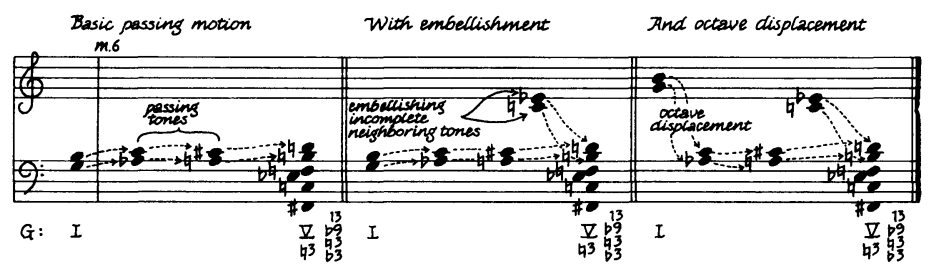

Example 4

Following the inverted dominant thirteenth chord, tonic harmony returns briefly ( $m$. 7). Then an essentially passing motion to subdominant harmony takes place (mm. 7-9). Finally, the piece concludes with a plagal cadence (m. 9). The terminal chord of this cadence is a tonic major seventh with major and minor thirds and added minor sixth. As such, it represents a considerable extension of the traditional harmonic vocabulary. The chord is composed of root (G), major third (B), minor third (B flat), fifth (D), seventh (F sharp), and added minor sixth ( $\mathrm{E}$ flat) (Ex. 5).

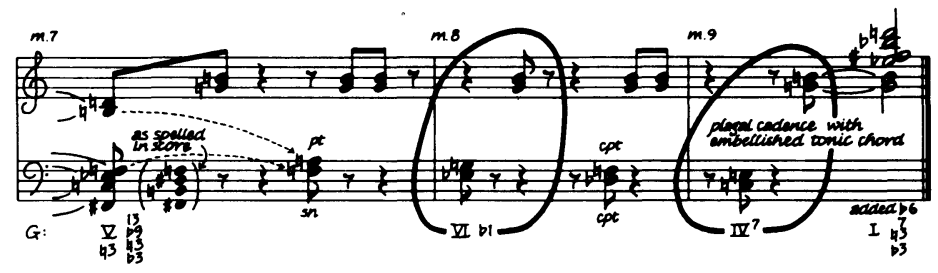

Example 5

The overall harmonic-melodic movement of which the foregoing are details is represented in Example 6 in nonrhythmic notation. Fundamental to the organization inherent in this movement is prolongation (in the Schenkerian sense) of the tonic triad. Means of prolongation, apart from simple reiteration of elements of the triad, include: (1) movement from tonic to each of the following harmonies and back: leading-tone, dominant, and subdominant; (2) passing motion.

The harmonic analysis of the piece in its entirety, given in stages in Examples 1-5, is presented uninterrupted in Example 7. So doing makes it easier for the reader to: (1) see the place of details within the context of the piece as a whole; and (2) relate the piece and its details to the overall harmonic-melodic movement (Ex. 6), and thus to the tonic triad being prolonged. 


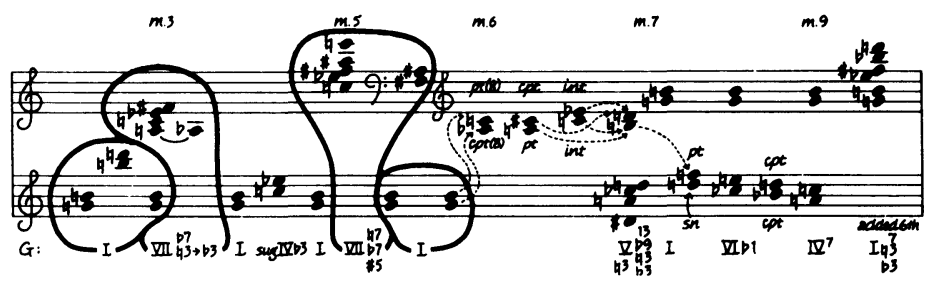

Example 6
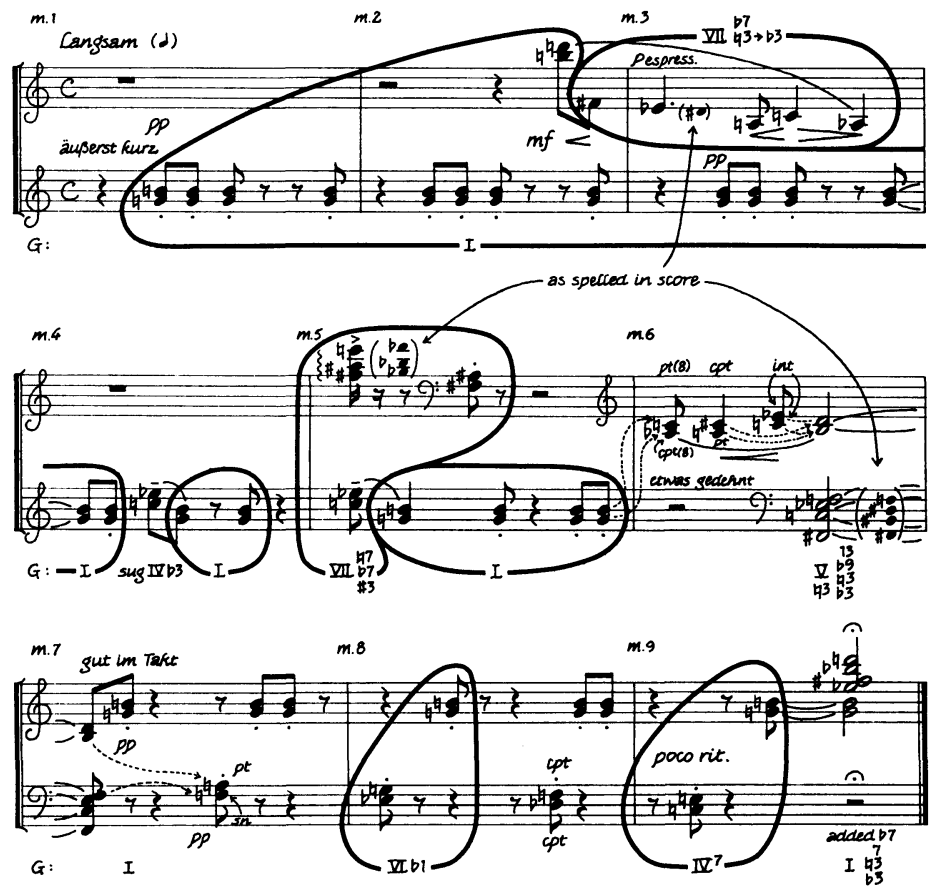

Example 7. Harmonic Analysis of Op. 19, No. 2

Piece VI illustrates (1) mono-tonal organization with modulation (mm. 1-7) and (2) fused-bitonal oganization (mm. 8-9). Tonal organization in the mono-tonal section may be sensed with reference to $C(\mathrm{~mm}$. 1-6) and then $D(\mathrm{~m}$. 7). In the fused-bitonal section, pitch is oriented with reference to centers $\mathrm{D}$ and $\mathrm{A}$ flat.

Initially, the analysis is illustrated via non-durational notation, which permits concentration upon matters of pitch organization without the added complexity of rhythm. Subsequently, both the piece and its analysis are offered in fullrhythmic notation. 
The piece commences with an initial, three-tone sonority, B F sharp A (Ex. 8a), to which a quartal triad, G C F, is then added (Ex. 8b). The first sonority may be understood in $C$ as comprising the root (B), fifth ( $F$ sharp), and seventh (A) of a third-less leading-tone ninth chord with raised fifth, whose ninth (C) enters as part of the quartal triad (Ex. 8c). This leading-tone chord, whose ninth is in its lowest voice, functions as a secondary dominant of the mediant.

The second sonority, a composite of the initial sonority and the quartal triad (Ex. 8b), is also a composite of the leadingtone ninth chord and of a dominant ninth chord in root position (Exx. 8c, 8d). The root $(G)$ and seventh $(F)$ of the latter come from the quartal tetrad; its third (B) and ninth (A) come from the initial sonority. The piece may thus be understood as commencing with movement from leading-tone (dominant of the mediant) harmony to a composite of this and dominant harmony (Ex. 8e).

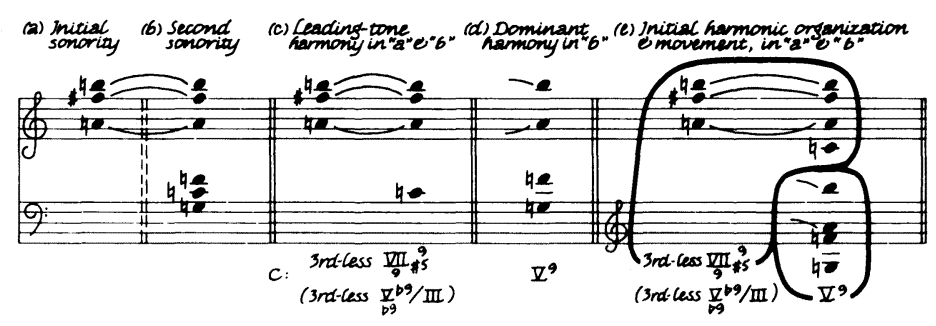

Example 8

This initial harmonic movement takes place twice again in the mono-tonal section ( $\mathrm{mm} .2-4,4-5)$. During part of the first recurrence (mm. 3-4), D sharp sounds, functioning as the previously missing third of the leading-tone chord and as a raised fifth in the dominant ninth. This D sharp occurs essentially in octaves, with the top tone of the octave embellished by an upper neighboring tone, E. In the second recurrence of the initial movement, the D sharp is again absent, as at the beginning (Ex. 9). 


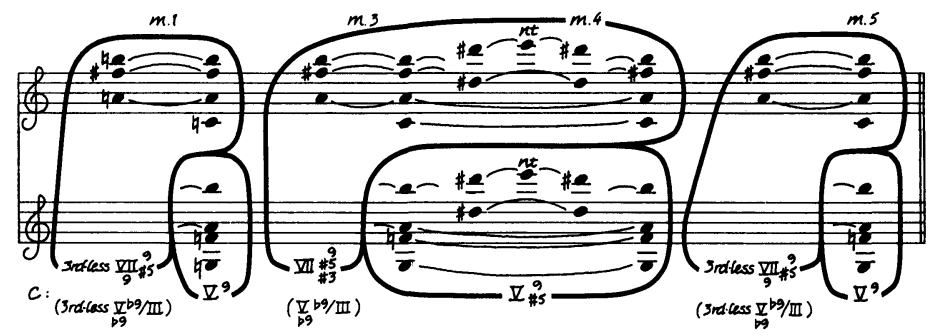

Example 9

The harmonic movement proceeds next through a quartal tetrad, G C F B flat, to a root-position statement of a mediant thirteenth chord with raised third and flat fifth: E G sharp B flat D F C (m. 5). The top three tones of this chord, that is, its thirteenth, (C), minor ninth (F) and flat fifth (B flat), are arranged as a quartal triad a fourth higher than the quartal triad at the bottom of the preceding leading-tone ninth dominant ninth composite chord. This composite chord, the quartal tetrad, and the mediant thirteenth chord are shown in Example 10.

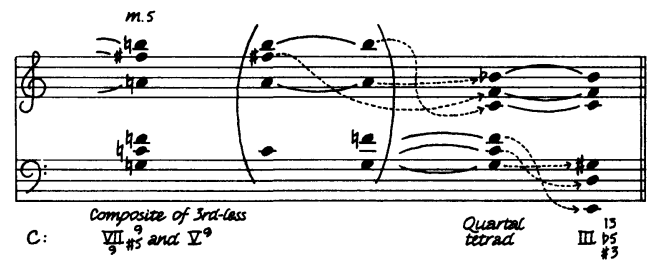

Example 10

Movement from the third-less leading-tone ninth dominant ninth composite chord to the mediant thirteenth chord is characterized by octave displacement in a majority of the voices. Without octave displacement, the movement in each voice would be by tone or semitone. This movement, firstly without octave displacement, then with it, and finally with it and with overlapping of quartal triads, is shown in Examples 11a, b, and c, respectively. 


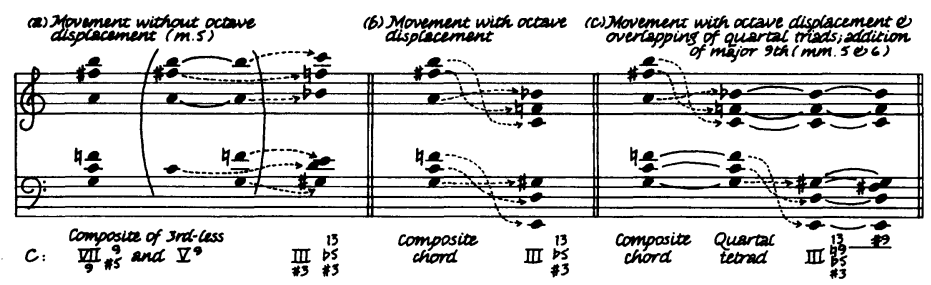

Example 11

After the thirteenth chord as a whole has commenced sounding, and while it continues to sound, its third ( $G$ sharp) moves to F sharp, a major ninth above the root, thus giving the chord a major as well as a minor ninth (m. 6). Because the damper pedal is depressed for the duration of this chord, the third also continues to sound, even though as a member of a voice it has moved (Ex. 11c).

The modulations in this piece are from $C$ to $D$, and then from $C$ to A flat. They take place via two pivot chords contained in a "parent" chord, the mediant thirteenth. The pivot chord used in going to $D$ is a supertonic ninth in that key, with raised third and lowered fifth: E G sharp B flat D F sharp. Four of its tones, E G sharp B flat D, constitute a French sixth on the flat submediant of $D$. The pivot chord used in going to A flat is a supertonic ninth in that key, with raised third and both perfect and flat fifths: B flat D F flat F A flat C. Also, four of its tones, $B$ flat D F flat A flat, constitute a French sixth on the flat submediant of A flat (Ex. 12).

(a)Parent 13th chord

(6) Pivat chord in D

(c) Pivot chord in $A D$

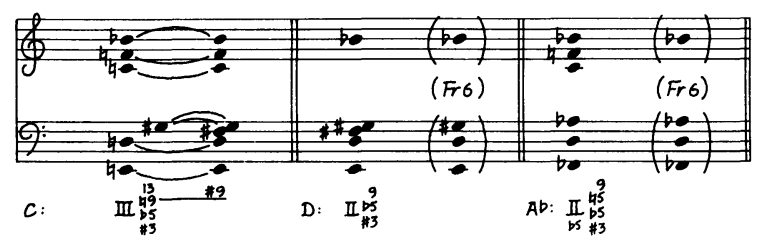

Example 12

Immediately after the mediant thirteenth chord, comes the brief D-oriented portion of the mono-tonal section, consisting essentially of a single root-position tonic triad whose fifth is implied but not present (m. 7). This chord, embellished by a lower neighboring tone, C sharp, is shown following the pivot 
chord, in Example 13. An octave-displaced chromatic passing tone, $\mathrm{D}$, is involved in movement to the next chord. In a very real sense the pivot chord in $\mathrm{D}$ has a $\mathrm{D}$ orientation. However, because that orientation is not perceived when the parent thirteenth chord is sounding, but is only understood in retrospect after the movement to the $\mathrm{D}$ tonic chord has taken place, this pivot chord is not included in the (audibly) D-oriented portion of the piece's mono-tonal section.

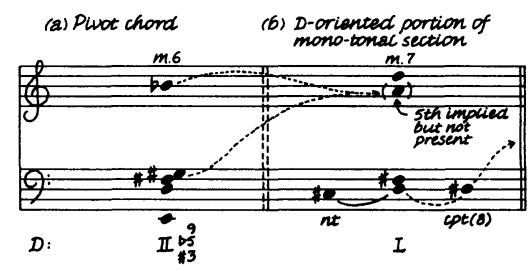

Example 13

The piece's fused-bitonal section, which is extremely short, follows next (mm. 8-9). As stated earlier, this section's simultaneous tonal centers are $D$ and $A$ flat. The aggregate of tones organized with reference to $D$ constitutes its "D component," and the aggregate of tones organized with reference to A flat, its "A flat component." Many of the section's tones are organized with reference to both centers at once, and thus belong to both components. The fused-bitonal organization, as such, may be understood as an integration of the tonal organization of the one component with that of the other. The section contains two fused-bitonal chords, each of which is a composite of elements from the components. In the ensuing discussion, the $\mathrm{D}$ and $\mathrm{A}$ flat components are first considered individually, then as integrated elements.

The $\mathrm{D}$ component may be understood as a continuation of the D-oriented portion of the mono-tonal section and preceding pivot chord in D. This relationship is demonstrated in Example 14 , where the component is shown following these other two items.

The component contains only two chords. The first of these (m. 8) is a root-position leading-tone ninth whose initially minor third becomes diminished. The chord is spelled C sharp E-becoming-E flat G B D. Its minor third (E) is approached by leap from the octave-displaced passing tone (D sharp) of the 


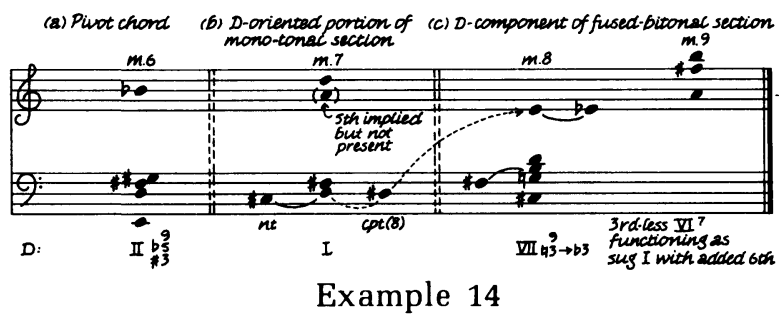

previous measure; its fifth $(G)$ is reached via upward movement from an untied suspension, F sharp (Ex. 14c). The second chord (m. 9) is the three-tone sonority B F sharp A with which the piece begins. Here its role is that of a third-less submediant seventh chord functioning as a suggested tonic triad with added sixth. The tonic triad is termed "suggested" because, although the tonic function may be perceived aurally, the root is not present except perhaps via combination tones (Ex. 14c).

The D-oriented portion of the mono-tonal section and the D component of the fused-bitonal section, just described, represent one of two tonal directions stemming from the mediant thirteenth chord (m. 6). The A flat component of the fused-bitonal section represents the other. Significantly, although both modulations start from the same place, from pivot chords contained in the same median-thirteenth parent chord, the modulation to $D$ takes place first (m. 7), and the one to A flat resumes essentially one measure later (m. 8), after having been interrupted as it were by the modulation to $D$.

As with its $D$ counterpart, the A flat component also contains only two chords. They, preceded by the pivot chord in A flat (m. 6), are shown in Example 15.

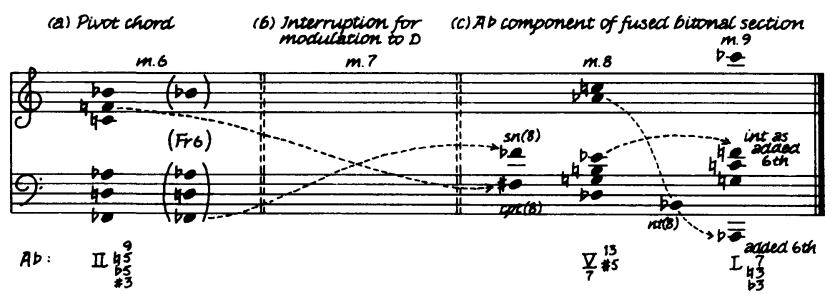

Example 15

The first of these chords (m. 8) is a dominant thirteenth having raised fifth and no ninth: $E$ flat $G B D$ flat $A$ flat $C$. Its seventh ( $D$ flat) is in the bass. Its third $(G)$ is approached by 
upward movement from an octave-displaced chromatic passing tone, $F$ sharp, and its root ( $E$ flat) from an octave-displaced untied suspension, F flat (Ex. 15c).

The second chord (m. 9) is a root-position tonic having major and minor thirds, no fifth, major seventh, and an added sixth: A flat C flat C F G. The F added sixth may be understood as an incomplete upper neighboring tone of the root ( $E$ flat) of the preceding dominant chord. As such, it may also be understood as a substitute for the absent fifth of the tonic chord. The $B$ flat preceding the tonic chord may be regarded as an octavedisplaced neighboring tone (Ex. 15c).

As indicated earlier, a fused-bitonal passage may be regarded as an integration of its tonal components, and its harmonic vocabulary and grammar may be understood in terms of integration of the harmonic vocabulary and grammar of one component with the harmonic vocabulary and grammar of the other. Such is the case with the fused-bitonal section of this piece.

This section contains three principal chordal items, that is, two septads in measure 8 and one in measure 9. The measure 8 septads, spelled C sharp F sharp B D E G sharp C and C sharp G B D E flat G sharp C, have five tones in common, C sharp B D G sharp $C$, which are tied together. The other two tones of the first septad, E and F sharp, move to $E$ flat and G, respectively, of the second. These two septads, viewed fused-bitonally, are a complex but single entity undergoing slight internal movement; an entity consisting simultaneously of: (1) the D component's measure 8 leading-tone ninth chord and attendant rising suspension; and (2) the A flat component's measure 8 dominantthirteenth chord and attendant octave-displaced suspension and octave-displaced chromatic passing tone. The measure 9 septad, A flat G C F A F sharp B, is a composite of: (1) the D component's third-less submediant seventh chord functioning as a suggested tonic triad with added sixth; and (2) the A flat component's root-position tonic chord having major and minor thirds, major seventh, and added sixth (Ex. 16).

Most of the tones of the three septads have dual harmonic functions. For example, the $C$ sharp of the first and second serves both as the root of the leading-tone ninth chord in $\mathrm{D}$ and, enharmonically respelled as $D$ flat, as the seventh of the dominant thirteenth chord in A flat. Similarly, the B of the third 

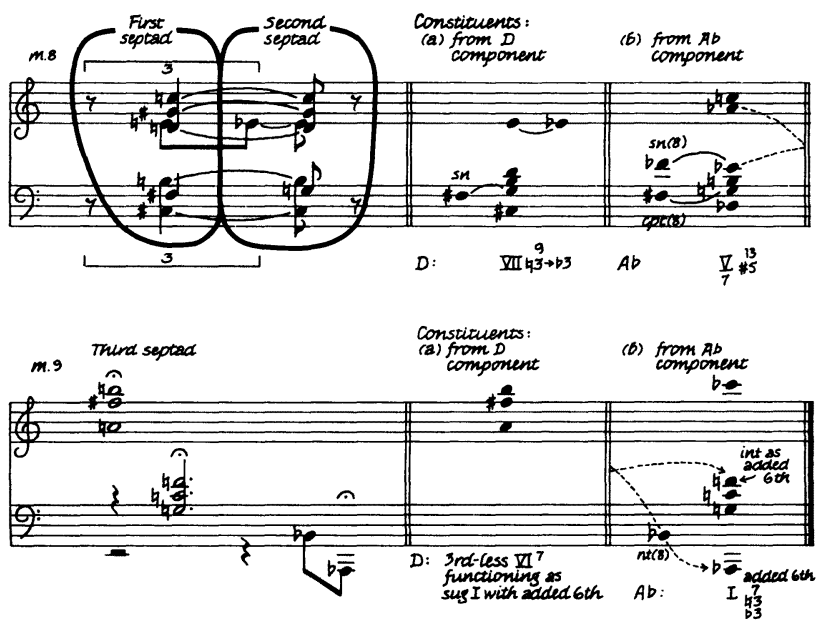

Example 16

septad functions both as the added sixth of the suggested tonic triad with added sixth in $D$ and, enharmonically respelled as $C$ flat, as the minor third of the A flat tonic chord.

At any given moment in a fused-bitonal passage, one of the components may be aurally more prominent than the other. In measure 8 of this piece, the dominant thirteenth chord in A flat predominates aurally over the leading-tone ninth chord in $D$. On the other hand, in measure 9, when the third-less submediant seventh chord enters, the $D$ orientation is stronger than that of A flat. However, by the time the remaining tones of the septad have entered, the A flat centrality again predominates.

The harmonic analysis of Piece VI, appearing thus far in installments, is next presented in its entirety, offering thereby: (1) an overview of the harmonic workings of the piece as a whole, and (2) a context within which details can be related both to each other and to the whole. The analysis is given using non-durational and then full-rhythmic notation in Examples 17 and 18 , respectively. The reader may find it profitable to compare these two examples, regarding the first as portraying the piece's harmonic "skeleton," and the second as showing a "fleshed-out" unfoldment of that skeleton via the agency of rhythm. In Example 18, both the score and the analysis appear together, the latter in measure-for-measure alignment beneath the former. This arrangement facilitates relating the analysis to the music itself. 

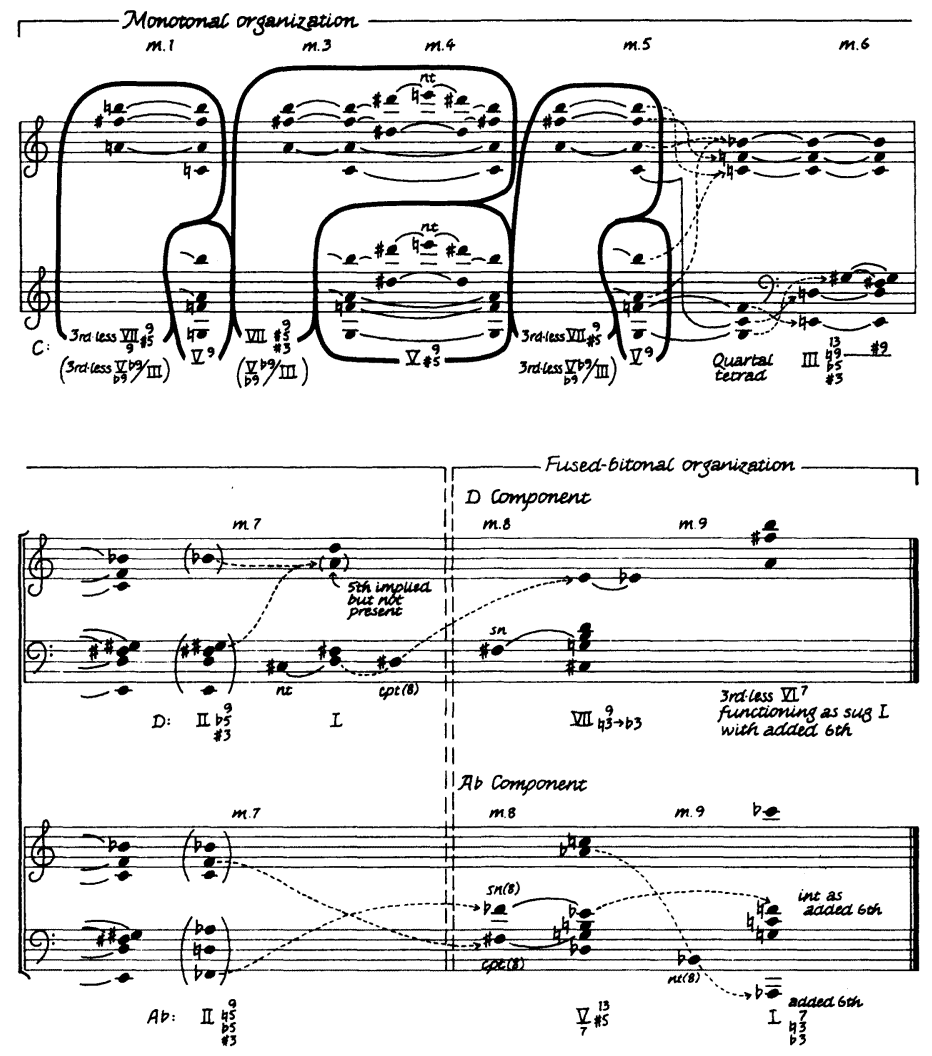

Example 17. Harmonic Analysis of Op. 19, No. 6 (non-durational notation)

The foregoing analyses represent a substantiation of the assertion made earlier that pitch in Schoenberg's Op. 19 is organized with reference more to extension than abandonment of tonality, according to two observed modes of extension: "mono-tonality" (extended tonal chromaticism) and "fusedbitonality." The issue raised by such substantiation is of course whether or not pitch in this composer's atonal and twelve-tone music as a whole is so organized, and more fundamentally, whether the atonality of this music is thus to be understood in terms of extension rather than of abandonment of tonality. 
score

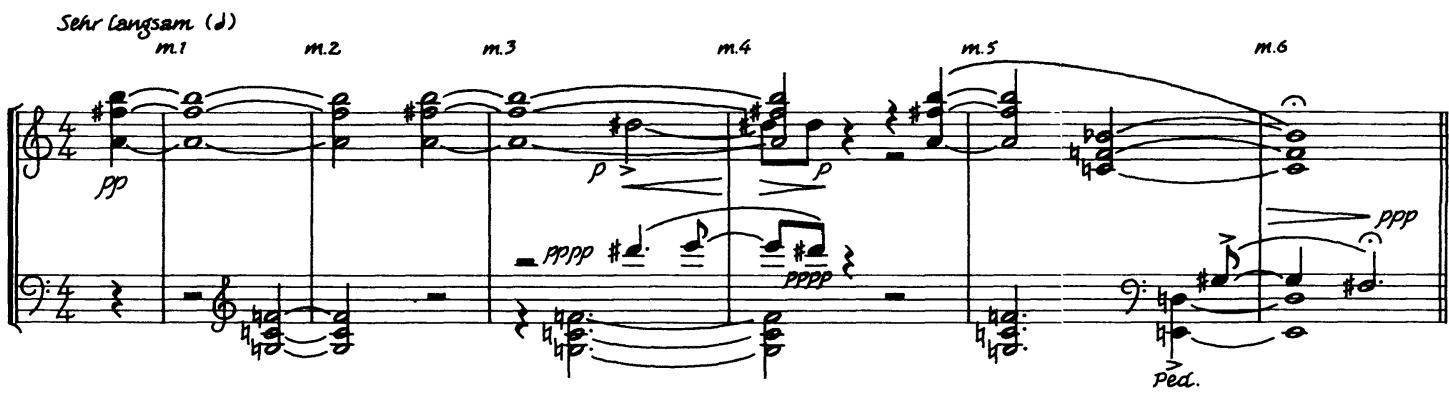

Analysis

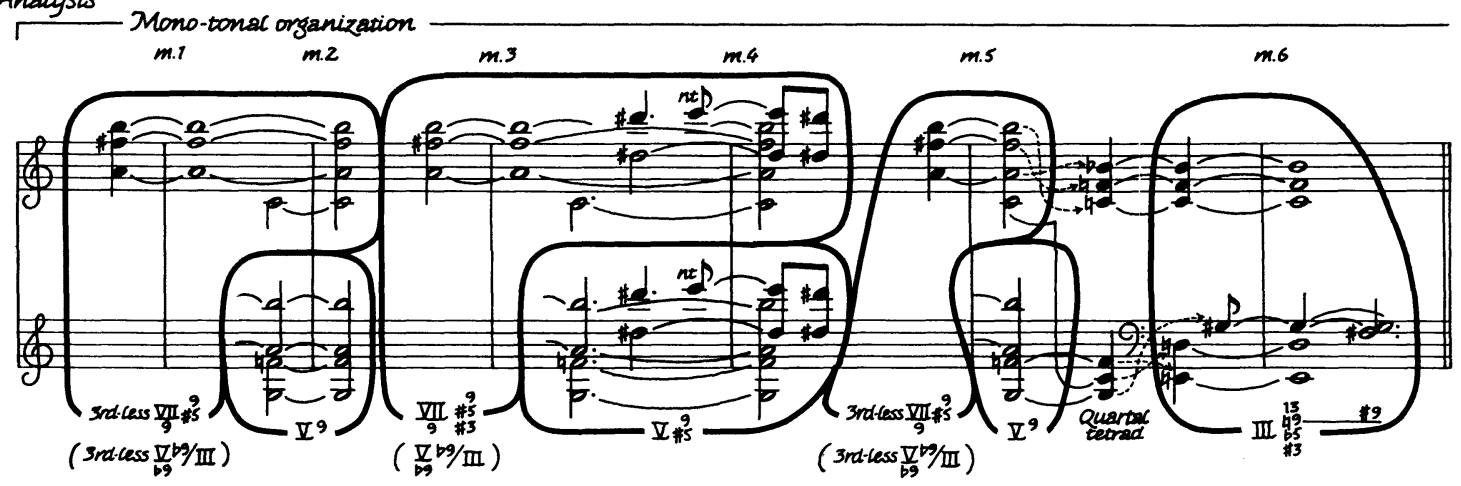

Example 18. Harmonic Analysis of Op. 19, No. 6 (full-rhythmic notation) 


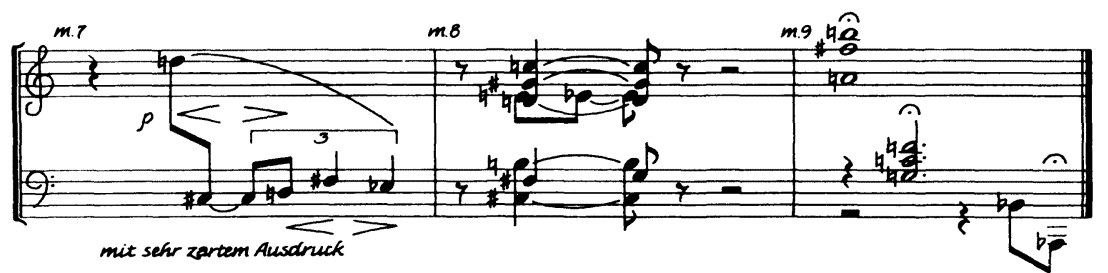

Piwot chords

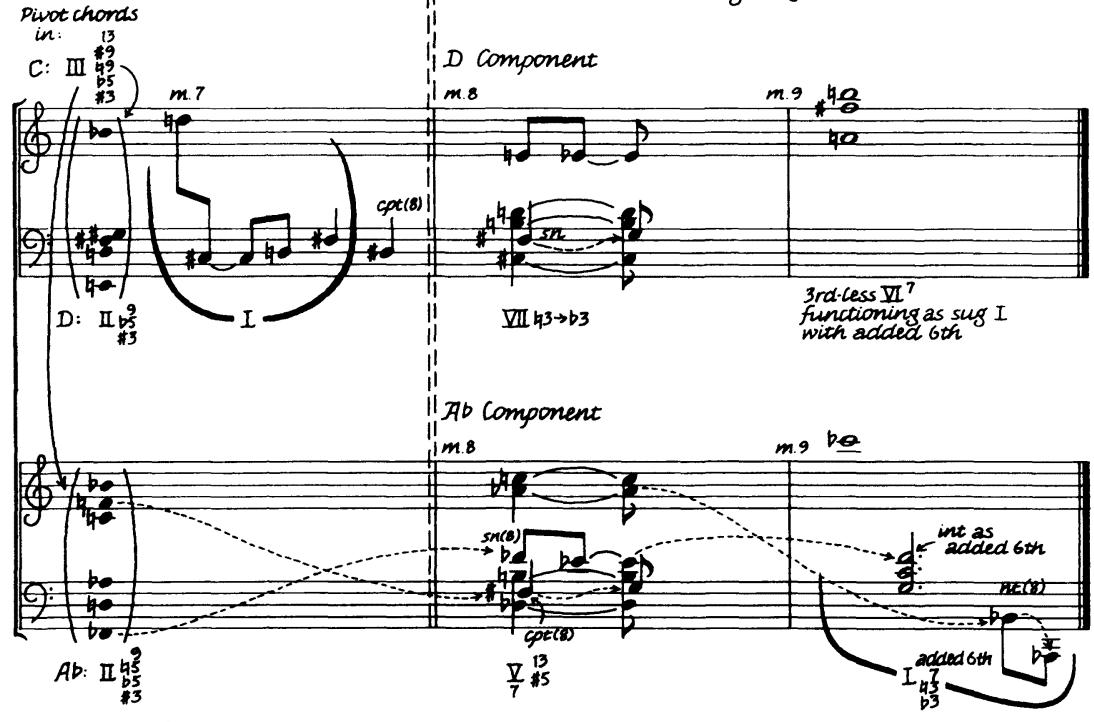

Fused-bitonac organization

Example 18 (continued). Harmonic Analysis of Op. 19, No. 6

(full-rhythmic notation) 